\title{
Sensitivity of freshwaters to browning in response to future climate change
}

\author{
Gesa A. Weyhenmeyer ${ }^{1} \cdot \operatorname{Roger}$ A. Müller $^{1}$ • \\ Maria Norman $^{2,3} \cdot$ Lars J. Tranvik ${ }^{1}$
}

Received: 28 May 2015 / Accepted: 16 September 2015 /Published online: 25 September 2015

(C) The Author(s) 2015. This article is published with open access at Springerlink.com

\begin{abstract}
Many boreal waters are currently becoming browner with effects on biodiversity, fish production, biogeochemical processes and drinking water quality. The question arises whether and at which speed this browning will continue under future climate change. To answer the question we predicted the absorbance $\left(\mathrm{a}_{420}\right)$ in 6347 lakes and streams of the boreal region under future climate change. For the prediction we modified a numerical model for $\mathrm{a}_{420}$ spatial variation which we tested on a temporal scale by simulating $\mathrm{a}_{420}$ inter-annual variation in 48 out of the 6347 Swedish waters. We observed that inter-annual $\mathrm{a}_{420}$ variation is strongly driven by precipitation that controls the water flushing through the landscape. Using the predicted worst case climate scenario for Sweden until 2030, i.e., a $32 \%$ precipitation increase, and assuming a $10 \%$ increase in imports of colored substances into headwaters but no change in land-cover, we predict that $\mathrm{a}_{420}$ in the 6347 lakes and streams will, in the worst case, increase by factors between 1.1 and 7.6 with a median of 1.3 . This increase implies that $\mathrm{a}_{420}$ will rise from the present $0.1-86 \mathrm{~m}^{-1}$ (median: $7.3 \mathrm{~m}^{-1}$ ) in the 6347 waters to $0.1-154 \mathrm{~m}^{-1}$ (median: $10.1 \mathrm{~m}^{-1}$ ), which can cause problems for the preparation of drinking water in a variety of waters. Our model approach clearly demonstrates that a homogenous precipitation increase results in very heterogeneous $\mathrm{a}_{420}$ changes, where lakes with a long-term mean landscape water retention time between 1 and 3 years are particularly vulnerable to climate change induced browning. Since these lake types are quite often used as drinking water resources, preparedness is needed for such waters.
\end{abstract}

Electronic supplementary material The online version of this article (doi:10.1007/s10584-015-1514-z) contains supplementary material, which is available to authorized users.

Gesa A. Weyhenmeyer

gesa.weyhenmeyer@ebc.uu.se

1 Department of Ecology and Genetics/Limnology, Uppsala University, Norbyvägen 18D, 752 36 Uppsala, Sweden

2 Department of Earth Sciences, Air- and Water Science, Uppsala University, Villavägen, 752 36 Uppsala, Sweden

3 Department of Environmental Science and Analytical Chemistry, Stockholm University, 106 91 Stockholm, Sweden 


\section{Introduction}

Clean water is a precious resource, and many expensive efforts are made globally to protect or create this commodity, in particular for drinking water (Richardson 2007). While particles can easily be removed from the water column by various filtration techniques, the removal of dissolved colored substances, commonly referred to as chromophoric dissolved organic matter, is far more complex and expensive (Eikebrokk et al. 2004; Volk et al. 2002). Chromophoric dissolved organic matter is usually dominated by brown-colored humic substances from terrestrial ecosystems (Thurman 1985), and frequently measured as absorbance of filtered water at a given wavelength, for example, $420 \mathrm{~nm}\left(\mathrm{a}_{420}\right)$ (Kirk 2003). In Swedish boreal surface waters, $a_{420}$ is among the water chemical variables that showed fastest change during the past decades, implying that waters appear increasingly brownish (Weyhenmeyer 2008). Accelerated browning of freshwaters has been reported from most northern European countries as well as North America (reviewed by Monteith et al. 2007). Browning has frequently been associated with increasing concentrations of dissolved organic carbon (DOC) (Roulet and Moore 2006), and more recently also with increasing concentrations of iron (Kritzberg and Ekström 2012). For water quality managers, politicians and society there is now an urgent need to know in how far browning of freshwaters might continue in the near future, and if the browning process is equally fast in the millions of lakes and streams of the boreal region. To fill this knowledge gap, a water color model that can be applied to a large variety of inland waters is needed.

At present only rather few water color models are available of which none has been used to predict the future water color in freshwaters across a large geographical region. Many more models are available for the prediction of DOC. Considering the close relationship between DOC and $\mathrm{a}_{420}$ in waters (Pace and Cole 2002), DOC models might be applicable for the prediction of water color, provided that they are modified to account for the preferential loss of color to carbon during transport through the landscape (Molot and Dillon 1997). On the spatial scale, DOC has been found to be mainly influenced by land-cover, in particular the percentage of wetland and open water in the catchment and the type of vegetation (e.g., Canham et al. 2004; Kortelainen 1993; Larsen et al. 2011; Sobek et al. 2007; Xenopoulos et al. 2003). On the temporal scale, DOC variation has been attributed to variation in hydrology (Erlandsson et al. 2008), air temperature (Winterdahl et al. 2014) and the recovery from acid deposition (Evans et al. 2006; Monteith et al. 2007). From the numerous DOC studies it becomes clear that main drivers of DOC, and thereby most likely also of $\mathrm{a}_{420}$, are not necessarily coherent between the spatial and temporal scale. This is problematic when predictions for thousands of waters across a large geographical region need to be made, which is often requested by managers and politicians. In an ideal world, models that have been calibrated and validated on a temporal scale should be used for predictions but such models are not available for the majority of waters. If we want to know the fate of browning of freshwaters across a large geographical region we need to rely on spatial models that are transferable to the temporal scale. Such models are not yet available for $\mathrm{a}_{420}$. Our intention was therefore to test whether an existing numerical model for spatial $\mathrm{a}_{420}$ variation is transferable to the temporal scale. The existing $\mathrm{a}_{420}$ model accounts for the rapid $\mathrm{a}_{420}$ loss during transport through the landscape (Müller et al. 2013). We extended the model and predicted $\mathrm{a}_{420}$ spatial variation across 6347 Swedish boreal lakes and streams. As a next step we tested the model on the temporal scale by simulating $\mathrm{a}_{420}$ inter-annual variation in 48 out of the 6347 waters from 1988 to 2012. As a final step, we 
predicted $\mathrm{a}_{420}$ for the 6347 lakes and streams under future climate change. To simulate the maximum possible climate change induced change of $\mathrm{a}_{420}$ in Swedish inland waters which is important to know for managers and politicians we used the predicted worst case climate scenario for Sweden until 2030.

\section{Methods}

\subsection{Lake and stream data}

From the Swedish national freshwater inventory program we had water chemical and catchment data from 6035 lakes and 312 streams that are evenly distributed over Sweden (Fig. S1 in supplementary). All data can freely be downloaded at http://webstar.vatten.slu.se/db.html. The 6347 lakes and streams represent inland waters of the boreal and hemiboreal region. The lakes were small (median lake area: $0.4 \mathrm{~km}^{2}$ ) and shallow (median mean lake depth: $3.9 \mathrm{~m}$ ). Both lakes and streams were generally nutrient-poor (median total phosphorus concentrations: $10 \mu \mathrm{g} \mathrm{L}^{-1}$ ) and humic (median total organic carbon concentrations: $9.1 \mathrm{mg} \mathrm{L}^{-1}$; median $\mathrm{pH}$ : 6.5). In this study, we used the absorbance of filtered $(0.45 \mu \mathrm{m}$ filter $)$ water at $420 \mathrm{~nm}$ in a $5 \mathrm{~cm}$ cuvette as a measure of the color of water, which we further transferred to the Napierian absorption coefficient $\left(\mathrm{a}_{420}\right)$ as recommended by $\mathrm{Hu}$ et al. (2002) (see supplementary). In addition, we used sulfate concentrations $\left(\mathrm{SO}_{4}-\mathrm{S}\right)$ in inland waters as a proxy for the influence of acid deposition. All samples were collected at a water depth of $0.5 \mathrm{~m}$ and analyzed by the certified water analyses laboratory at the Swedish University of Agricultural Sciences according to standard limnological methods during the past 40 years. A detailed method description including analytical precision and range is available at http:/www.slu.se/en/departments/ aquatic-sciences-assessment/laboratories/geochemical-laboratory/water-chemical-analyses/.

For the assessment of $\mathrm{a}_{420}$ spatial variation across the 6347 waters we used site-specific long-term median values during autumn when the water column is mixed (for a detailed description of sampling design and data selection see supplementary). Out of the 6347 waters we had 24 small boreal lakes and 24 small boreal streams with complete monthly time series (for lakes during the ice-free season May to October) during 1988 to 2012 (for location of the 48 waters see Fig. S1 in supplementary). The 48 waters were used to assess inter-annual $\mathrm{a}_{420}$ variation. Land-cover in the catchments of the 48 waters has not substantially changed during the time period 1988 to 2012.

\subsection{Catchment and meteorological data}

For each of the 6347 inland waters we had GIS-derived data on a variety of catchment variables (resolution: $100 \mathrm{~m} \times 100 \mathrm{~m}$; Table 1). For lakes, we also had data on mean depth and surface area. Using GIS we overlapped the lake and stream database with the database on meteorological variables from the Swedish Meteorological and Hydrological Institute at http:// www.smhi.se and downloaded site-specific (i.e., interpolated data at the sampling point) longterm means of annual precipitation $\left(\mathrm{P}_{1961-1990}\right)$, annual surface water runoff $\left(\mathrm{R}_{1961-1990}\right)$, annual mean air temperature (MAT $1961-1990)$, growing degree days $\left(\mathrm{GDD}_{1961-1990}\right)$ and annual global radiation $\left(\mathrm{RAD}_{1961-1990}\right)$ (for detailed description and units see Table 1). For the 48 waters with monthly data we also downloaded site-specific MAT and site-specific annual precipitation (P) during 1988 to 2012 from http://www.smhi.se according to the procedure 
described above. In addition, we downloaded annual mean precipitation for the whole of Sweden during 1988 to 2012, as well as the predicted worst case climate scenario for Sweden until 2030 (for a detailed description of the determination of Sweden's climate scenarios see supplementary).

\subsection{Modeling approach}

\subsubsection{Statistical evaluation of $a_{420}$ variation}

All statistical tests, including common statistical measures such as mean, median, and simple linear regressions as well as non-parametric tests, were run in JMP, version 11.0.0. A variety of variables were not normally distributed, tested by applying a Shapiro-Wilk test. We therefore used statistical tests that are insensitive to deviations from normality. These tests were: A) nonparametric Wilcoxon-test for group comparisons, B) non-parametric Kendall's tau test for correlations between variables, C) partial least squares regression models (PLS) for the predictions of $\mathrm{a}_{420}$, and D) non-parametric Mann-Kendall trend tests to analyze changes over time. For the Mann-Kendall test we used annual mean values. From the test results we calculated changes over time in percentage by dividing the Theil slope by median values of 1988 to 2012 (for more detailed information on the statistical tests we refer to the supplementary).

\subsubsection{Model for $a_{420}$ spatial variation}

Spatial variation in $\mathrm{a}_{420}$ has previously been modeled with the following approach (Müller et al. 2013):

$$
a_{420}=a_{420, \text { headwater }} \cdot \exp \left(-\lambda \cdot W R T_{1961-1990}\right)
$$

where $\mathrm{a}_{420}$ corresponds to $\mathrm{a}_{420}$ at a sampling site (in $\mathrm{m}^{-1}$ ), $\mathrm{a}_{420 \text {,headwater }}$ is $\mathrm{a}_{420}$ in the headwaters of the site (in $\mathrm{m}^{-1}$ ), $\lambda$ is the $\mathrm{a}_{420}$ decay rate in the landscape (in days ${ }^{-1}$ ) and WRT $_{1961-1990}$ is the site-specific long-term mean (1961-1990) landscape water retention time

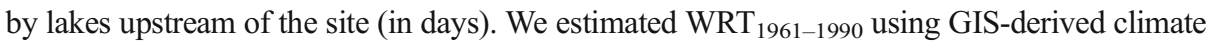
and catchment data (see supplementary) and received the following model for $\mathrm{a}_{420}$ spatial variation:

$$
a_{420}=a_{420, \text { headwater }} \cdot \exp \left(-\lambda \cdot \frac{\text { Lakedepth }_{\text {mean }} \cdot \text { Lakearea }_{\text {sum }}}{R_{1961-1990} \cdot C A}\right)
$$

(for abbreviations and variable/parameter explanations including units see Table 1). We used

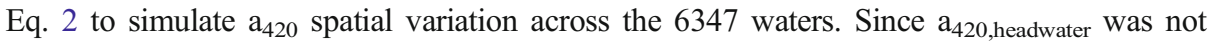

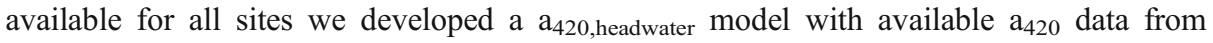
headwaters. Out of the 6347 freshwaters we classified 291 waters as headwaters (249 lakes and 42 streams). We defined headwaters as waters that had zero percentage of upstream lake surface area in the catchment area. This classification implies that some higher-order streams are included in the category of headwaters. For the $\mathrm{a}_{420 \text {,headwater }}$ model we first identified major climate and catchment drivers for $\mathrm{a}_{420}$ variation in headwaters using PLS. We then developed an $\mathrm{a}_{420 \text {,headwater }}$ model with the main drivers as input variables and used it to predict $\mathrm{a}_{420 \text {,head- }}$ water for the 6347 sites. As a final step we modeled $\mathrm{a}_{420}$ spatial variation across the 6347 Swedish waters with Eq. 2 where the overall $\mathrm{a}_{420}$ decay rate in the landscape corresponded to 
Table 1 Model variables and calibrated parameters including their abbreviations and units

Variables Abbreviation Units

Lake and stream water variables

Long-term median absorbance of filtered water at $420 \mathrm{~nm}$

$\mathrm{a}_{420}$

$\mathrm{a}_{420}(\mathrm{t})$

$a_{420 \text {,headwater }}$ of year $\mathrm{t}$

Long-term median absorbance of filtered water at $420 \mathrm{~nm}$ in headwaters, here defined as waters that had zero percentage of upstream lake surface area in the catchment area

Annual mean of absorbance of filtered water at $420 \mathrm{~nm}$ in headwaters of year $\mathrm{t}$

Long-term median sulfate concentrations

$\mathrm{a}_{420 \text {,headwater }}(\mathrm{t})$

$\mathrm{m}^{-1}$

$\mathrm{SO}_{4}-\mathrm{S}$

$\mathrm{mEq} \mathrm{L} \mathrm{L}^{-1}$

Catchment variables

Size of catchment area of the inland water (in case a lake is considered CA excludes the area of the study lake)

Elevation of the sampling site

Percentage of agricultural land

Percentage of pasture

Percentage of coniferous forest

Percentage of deciduous forest

Percentage of mixed forest

Percentage of clear-cut (defined as forested area where the height of trees is $<2 \mathrm{~m}$ )

Percentage of open wetland

Percentage of land without vegetation including urban land cover

Sum of lake surface area in the catchment area, and in case a lake site is considered including the lake area of the study lake

Long-term mean of site-specific landscape water retention time (average 1961-1990), calculated according to eq. S2 in supplementary

Meteorological variables

Site-specific annual precipitation of year $t$

Long-term mean of site-specific annual precipitation (average 1961-1990)

Site-specific annual surface water runoff of year $t$

Long-term mean of site-specific annual surface water runoff (average 1961-1990)

Site-specific annual mean air temperature of year $\mathrm{t}$

Long-term mean of site-specific annual mean air temperature (average 1961-1990) which we altitude adjusted by $-0.6^{\circ} \mathrm{C}$ per $100 \mathrm{~m}$ according to Livingstone et al. (1999)

Long-term mean of site-specific growing degree days (average 1961-1990)

Long-term mean of site-specific annual global radiation (sum of direct and diffusive solar radiation within the spectral interval 280-4000 nm; average 1961-1990)
CA

Altitude

$\mathrm{m}^{2}$

$\%$ Agricultural land

$\mathrm{m}$ a.s.l.

$\%$ Pasture

$\%$ of CA

$\%$ of $\mathrm{CA}$

$\%$ Coniferous forest

$\%$ of CA

$\%$ Deciduous forest

$\%$ of $\mathrm{CA}$

$\%$ Mixed forest

$\%$ of $\mathrm{CA}$

$\%$ Clear-cut

$\%$ of $\mathrm{CA}$

$\%$ Open wetland $\%$ of CA

$\%$ Land without vegetation $\%$ of CA

Lakearea $_{\text {sum }}$

$\mathrm{m}^{2}$

WRT $_{1961-1990}$

Number of days
$\mathrm{P}(\mathrm{t})$

$\mathrm{P}_{1961-1990}$

$\mathrm{m} \mathrm{yr}^{-1}$

$\mathrm{R}(\mathrm{t})$

$\mathrm{R}_{1961-1990}$

$\mathrm{m} \mathrm{yr}^{-1}$

$\operatorname{MAT}(\mathrm{t})$

MAT $_{1961-1990}$

${ }^{\circ} \mathrm{C}$

${ }^{\circ} \mathrm{C}$

GDD $_{1961-1990}$

RAD $_{1961-1990}$
Number of days

$\mathrm{kWh} \mathrm{m}{ }^{-2}$ 
Table 1 (continued)

\begin{tabular}{lll}
\hline Variables & Abbreviation & Units \\
\hline $\begin{array}{l}\text { Parameters (for calibration of the parameters we refer to } \\
\text { the supplementary) }\end{array}$ & & \\
$\mathrm{a}_{420}$ decay rate in the landscape & $\lambda$ & day $^{-1} \mathrm{or} \mathrm{yr}^{-1}$ \\
$\begin{array}{l}\text { Mean lake depth in the catchment area through which } \\
\text { water flushes }\end{array}$ & Lakedepth $_{\text {mean }}$ &
\end{tabular}

0.001 day $^{-1}$ and Lakedepth ${ }_{\text {mean }}$ to $4 \mathrm{~m}$ (for a detailed description how the parameter values were derived we refer to the supplementary).

\subsubsection{Model transfer to the temporal scale}

Since our final goal was to predict $\mathrm{a}_{420}$ in the 6347 lakes and streams under future climate change we needed to test whether the $a_{420}$ spatial model is suitable for predictions on a temporal scale. We therefore transferred the $\mathrm{a}_{420}$ spatial model (Eq. 2) to the temporal scale according to:

$$
a_{420}(t)=a_{420, \text { headwater }}(t) \cdot \exp \left(-\lambda \cdot \frac{\text { Lakedepth }_{\text {mean }} \cdot \text { Lakearea }_{\text {sum }}}{R(t) \cdot C A}\right)
$$

(for abbreviations and variable/parameter explanations including units see Table 1). We tested the $\mathrm{a}_{420}$ model (Eq. 3 ) by simulating inter-annual $\mathrm{a}_{420}$ variation in 48 out of

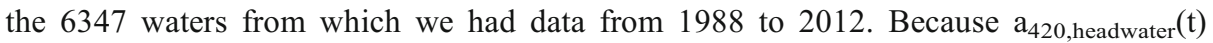
was not available for the 48 waters we predicted $a_{420 \text {,headwater }}(t)$ with the spatial

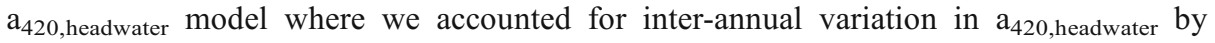
using inter-annual variations of the main driving variables (see supplementary). To apply Eq. 3 to our 48 waters we also needed an estimate for site-specific inter-annual variation in $\mathrm{R}$. For the estimation we multiplied site-specific $\mathrm{R}_{1961-1990}$ with the sitespecific annual precipitation deviation from $\mathrm{P}_{1961-1990}$. This approach assumes that changes in runoff are directly related to precipitation changes in a 1:1 relationship. Such an assumption results in maximum runoff changes which we consider being acceptable as a worst case scenario. It is the most suitable assumption for our modeling purpose taking into account the large variation in precipitation-runoff relationships over time and space.

\subsubsection{Model sensitivity analyses}

To demonstrate the sensitivity of the $a_{420}$ model (Eq. 3) to variations in input variables and parameters, i.e., to variations in headwater conditions, $\mathrm{a}_{420}$ decay rate, runoff and water flushing through the landscape, we performed model sensitivity

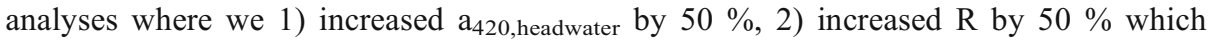
in our model is equivalent to a $50 \%$ decrease in the $\mathrm{a}_{420}$ decay rate in the landscape, and 3) decreased Lakedepth mean $_{\text {by }} 50 \%$, which reflects a runoff induced accelerated water flushing through the landscape. 


\section{Results}

\subsection{Spatial variation in $\mathbf{a}_{420}$ : observation and modeling}

The site-specific long-term median $\mathrm{a}_{420}$ of 6347 inland waters (6035 lakes and 312 streams) varied between 0.01 and $86 \mathrm{~m}^{-1}$ with a median of $7.2 \mathrm{~m}^{-1}$. Across the 291 headwaters (249 lakes and 42 streams out of the 6347 waters) the site-specific longterm median $\mathrm{a}_{420}$ ranged between 0.1 and $57 \mathrm{~m}^{-1}$, with no significant difference in $\mathrm{a}_{420 \text {,headwater }}$ between headwater streams and headwater lakes (non-parametric Wilcoxon test: $P>0.05$ ). We found that $\mathrm{a}_{420 \text {, headwater }}$ spatial variation was best explained by variation in MAT $_{1961-1990}$ when we used a PLS model with 16 catchment and climate variables as input variables (Table $\mathrm{S} 1$ in supplementary). $\mathrm{SO}_{4}-\mathrm{S}$ concentrations in the water were not important for the model performance (Table S1 in supplementary). MAT ${ }_{1961-1990}$ was highly significantly related to $\mathrm{GDD}_{1961-1990}$, $\mathrm{RAD}_{1961-1990}$ and variables describing the land-cover in the catchment of the headwaters, i.e., percentage of agricultural land, pasture, coniferous forest, deciduous forest, mixed forest, open wetland, and land without vegetation including urban land-cover (non-parametric Kendall's tau test: $P<0.0001$ ).

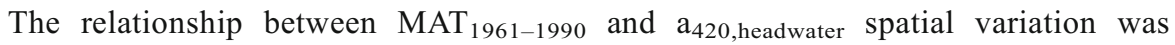

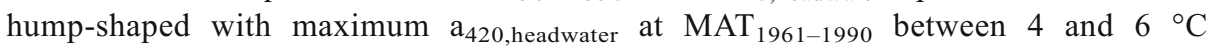
(Fig. 1). Using $\mathrm{MAT}_{1961-1990}$ as input variable for a simple Gaussian Peak Shape model (eq. S3 in supplementary) we were able to predict $57 \%(P<0.0001)$ of

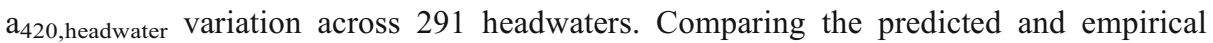
values, we received a slope of 1.03 and an insignificant intercept $(P>0.05)$. The

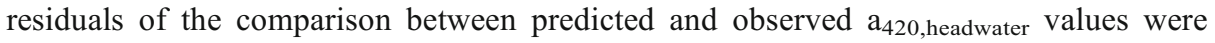
largest in the smallest catchments located in warmer geographical regions. Using the $\mathrm{a}_{420 \text {,headwater }}$ model (eq. $\mathrm{S} 3$ in supplementary) to predict $\mathrm{a}_{420 \text {,headwater }}$ for all 6347 sites we could, with Eq. 2, explain $54 \%$ of the $\mathrm{a}_{420}$ variation across the 6347 waters (Fig. 2a). Comparing the predicted and empirical values of $\mathrm{a}_{420}$ in the 6347 waters, we received a slope of 1.01 and an insignificant intercept $(P>0.05)$.

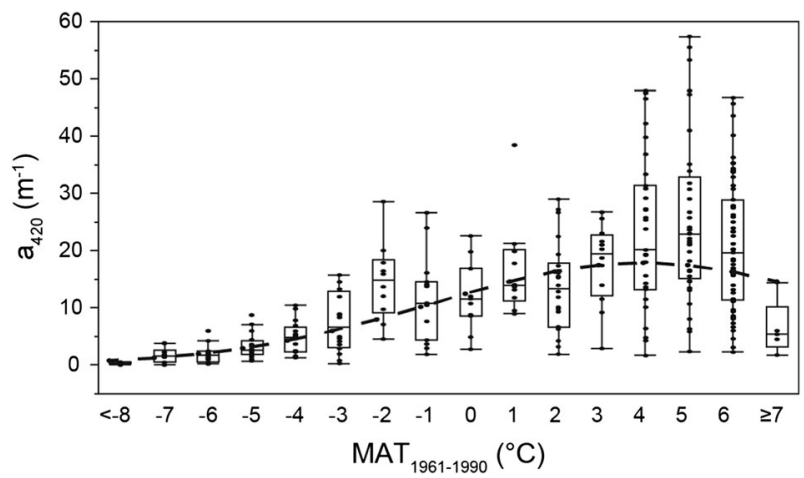

Fig. 1 Absorbance of filtered water at $420 \mathrm{~nm}\left(\mathrm{a}_{420}\right)$ in 291 Swedish headwaters (42 streams and 249 lakes) along a site-specific long-term mean (1961-1990) annual mean air temperature gradient (MAT ${ }_{1961-1990)}$. Each dot represents a site-specific long-term median $\mathrm{a}_{420}$ autumn value. Shown are box plots for each degree MAT $_{1961-1990}$. The curve represents predicted $\mathrm{a}_{420}$ values for each degree $\mathrm{MAT}_{1961-1990}$ according to Eq. $\mathrm{S} 3$ (see supplementary) 


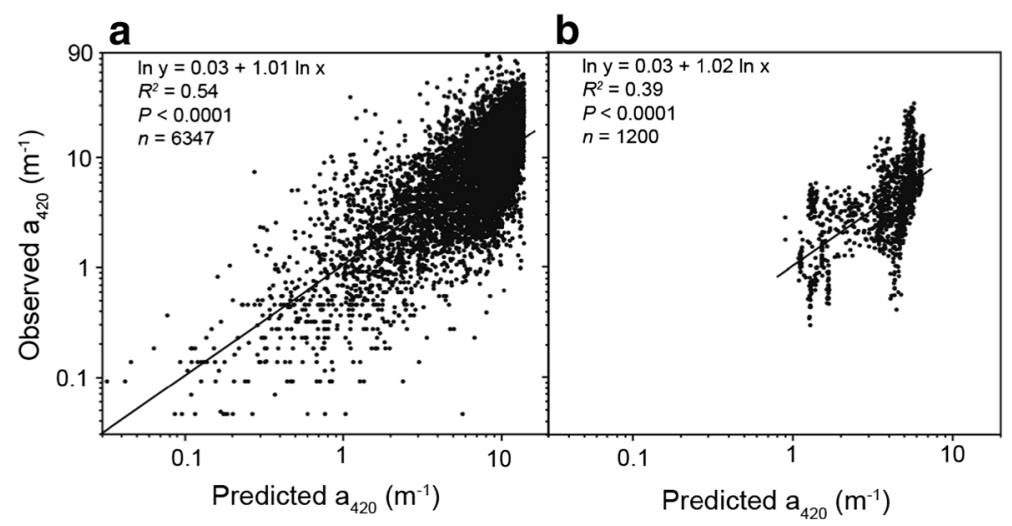

Fig. 2 Relationship between predicted and observed absorbance of filtered water at $420 \mathrm{~nm}\left(\mathrm{a}_{420}\right)$. Panel a shows the prediction on a spatial scale (long-term median autumn values) for 6347 lakes and streams using Eq. 2 (see text) and panel $\mathrm{b}$ shows the prediction on a temporal scale (inter-annual variation, based on annual means) for 24 lakes and 24 streams during 1988 to 2012 using Eq. 3 (see text)

\subsection{Inter-annual variation in $\mathbf{a}_{420}$ : observation and modeling}

Analyses of the data from the 48 waters (24 lakes and 24 streams) showed that the annual mean of $\mathrm{a}_{420}$ in the lakes and streams had changed between -43 and $139 \%$ with a median of $50 \%$ over the time period 1988 to 2012. Thus, during the past 25 years Swedish freshwaters have on average experienced an $\mathrm{a}_{420}$ increase by a factor of 1.5 . During the same time period mean annual precipitation across Sweden has increased by $14 \%$ from 650 to $740 \mathrm{~mm} \mathrm{yr}^{-1}$. In 32 of the 48 waters the increase in $a_{420}$ during 1988 to 2012 was significant (non-parametric Mann-Kendall-test: $P<0.05$ ). The strongest $\mathrm{a}_{420}$ trend occurred in a small boreal lake. The $\mathrm{a}_{420}$ trends were significantly higher in lakes compared to streams (non-parametric Wilcoxon-test: $P<0.01$ ). Changes over time in $\mathrm{a}_{420}$ (in $\% \mathrm{yr}^{-1}$ ) were significantly increased with increasing site-specific landscape $\mathrm{WRT}_{1961-1990}\left(R^{2}=0.35, P<0.05, n=48\right)$.

When we simulated the observed inter-annual $\mathrm{a}_{420}$ variation in the 24 lakes and 24 streams with Eq. 3 where $\mathrm{a}_{420 \text {,headwater }}(\mathrm{t})$ was modeled using site-specific inter-annual variations in MAT (eq. S4 in supplementary) we received a poor model performance: $R^{2}=0.10, P<0.0001, n=1200$, slope 0.56 , intercept: $P<0.01$. The model performance became better when we ignored inter-annual variation in MAT and kept MAT $1961-1990$ from the spatial scale: $R^{2}=0.36, P<0.0001, n=1200$. However, the slope of the relationship between predicted and empirical $\mathrm{a}_{420}$ still deviated substantially from 1.0 (i.e., the slope corresponded to 0.89 ) and the intercept was still significant. To receive a regression slope close to 1.0 and an insignificant intercept we needed to

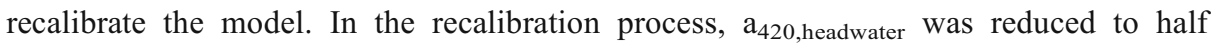

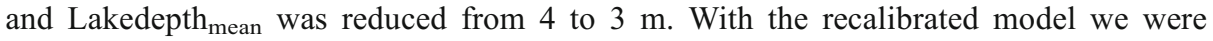
able to predict $39 \%$ of the $\mathrm{a}_{420}$ variation in the 48 waters (24 lakes and 24 streams) during 1988 to $2012(P<0.0001, n=1200$, slope 1.02 , intercept: $P>0.05$; Fig. $2 b)$. Analyzing inter-annual variation for each of the 24 lakes and 24 streams individually,

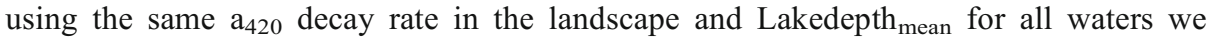
found significant relationships $(P<0.05)$ between predicted and observed $a_{420}$ values in 35 waters with highly varying $R^{2}$ values. 


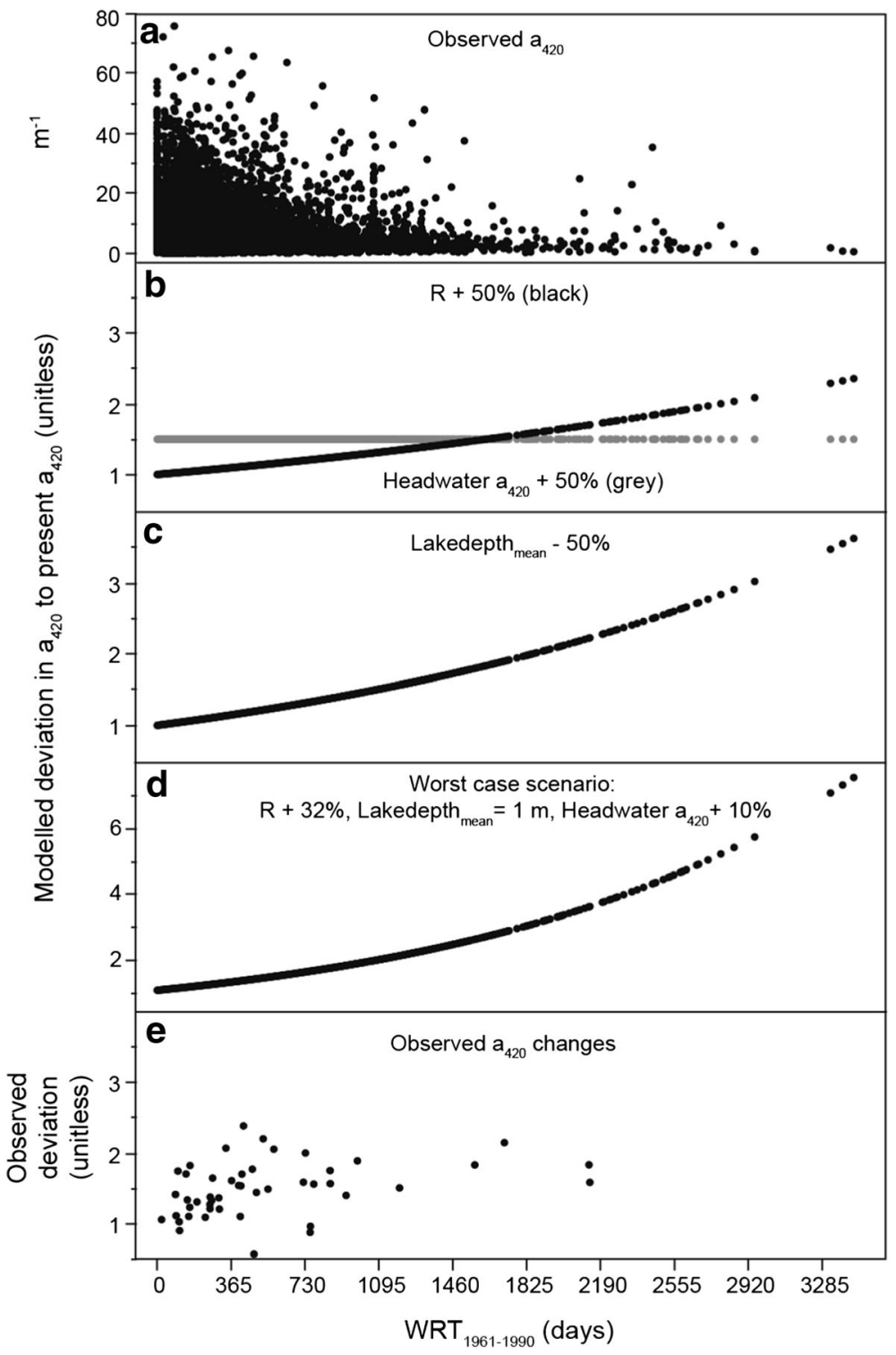

Fig. 3 Sensitivity of the absorbance of filtered water at $420 \mathrm{~nm}\left(\mathrm{a}_{420}\right)$ in 6347 Swedish inland waters to changes in surface water runoff $(\mathrm{R})$, headwater conditions and mean lake depth in the catchment area through which water flushes $\left(\right.$ Lakedepth $\mathrm{mean}_{\text {) }}$ along a site-specific long-term mean (1961-1990) landscape water retention time gradient (WRT $1961-1990)$. Panel a shows observed long-term median $\mathrm{a}_{420}$ autumn values in 6347 inland waters. Panel b-e show model results. We ran our $\mathrm{a}_{420}$ model $(\mathrm{nn})$ four times with varying values for variables and parameters and plotted the deviations from the present modeled $\mathrm{a}_{420}$ values for each of the 6347 inland waters. First we increased R by $50 \%$ (panel b), second we increased $\mathrm{a}_{420}$ in headwaters by $50 \%$, third we decreased Lakedepth $_{\text {mean }}$ by $50 \%$ (panel c), and finally we used the simulated worst case climate scenario for Sweden for 2030 with an increase in R by $32 \%$, a decrease in Lakedepth $\mathrm{mean}_{\text {to }} 1 \mathrm{~m}$ and an increase in headwater $\mathrm{a}_{420}$ by $10 \%$ (panel e). In panel e we plotted observed changes in $\mathrm{a}_{420}$ in 24 lakes and 24 streams over the time period 1988 to 2012 


\subsection{Model sensitivity and future $\mathbf{a}_{420}$ development}

The $\mathrm{a}_{420}$ model (Eq. 3) was most sensitive to variations in the water flushing through the landscape, i.e., Lakedepth $\mathrm{mean}_{\text {. When we reduced Lakedepth }}$ mean by $50 \%$ we received $\mathrm{a}_{420}$ changes in the 6347 inland waters by factors between 1.0 and 3.6 with a median of 1.1. Similar effects but less pronounced were found when we increased $\mathrm{R}$ by $50 \%$; here $\mathrm{a}_{420}$ changed by factors between 1.0 and 2.4 with a median of 1.1 . The $\mathrm{a}_{420}$ response to changes in Lakedepth $_{\text {mean }}$ and R became increasingly pronounced along the $\mathrm{WRT}_{1961-1990}$ gradient (Fig. $3 \mathrm{~b}$ and c). This is in contrast to the $\mathrm{a}_{420}$ response to changes in headwater conditions.

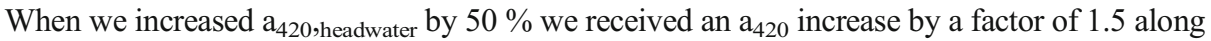
the entire $\mathrm{WRT}_{1961-1990}$ gradient (Fig. 3b). Thus, according to the model an increase in $\mathrm{a}_{420}$ in headwaters results in similar $\mathrm{a}_{420}$ increases in all waters while changes in Lakedepth $\mathrm{h}_{\text {mean }}$ and $\mathrm{R}$ affect particularly waters with a longer WRT $1961-1990$.

Considering the worst case climate scenario for Sweden until 2030 with a maximum R increase by $32 \%$, we predict that $\mathrm{a}_{420}$ will change by factors between 1.0 and 1.9 with a median of 1.1. Adding to the runoff increase also a $10 \% \mathrm{a}_{420}$ increase in headwaters, and considering a runoff induced accelerated water flushing through the landscape which we achieved by reducing Lakedepth $\mathrm{h}_{\text {mean }}$ to $1 \mathrm{~m}$, we predict that $\mathrm{a}_{420}$ in Swedish lakes and streams will, at a maximum, increase by factors between 1.1 and 7.6 with a median of 1.3 , provided that land-cover does not change (Fig. 3d). These changes are larger than the observed $\mathrm{a}_{420}$ changes in the 24 lakes and 24 streams during 1988 to 2012 (Fig. 3e).

\section{Discussion}

The modeling results show that many of the several hundred thousand freshwaters in Sweden will continue to become browner under the predicted worst case climate change scenarios for Sweden (Fig. 4). Most pronounced changes in $\mathrm{a}_{420}$ under the worst case scenario with a factor of more than 4 will occur in waters that have a $\mathrm{WRT}_{1961-1990}>6$ years (Fig. 3d). Waters with WRT $_{1961-1990}>6$ years are not very common in the boreal region, and $\mathrm{a}_{420}$ in these waters is usually low (Fig. 3a). Thus, a strong relative change in $\mathrm{a}_{420}$ in the boreal region commonly results in only moderately high $\mathrm{a}_{420}$. Far more common in the boreal region are waters with WRT $_{1961-1990}<3$ years (Müller et al. 2013). In these waters $\mathrm{a}_{420}$ is usually high (Fig. 3a), in particular in the warm and nutrient-rich southern part of Sweden (Fig. 4a). We predicted that maximum $\mathrm{a}_{420}$ under the worst case climate change scenario for Sweden will be reached in

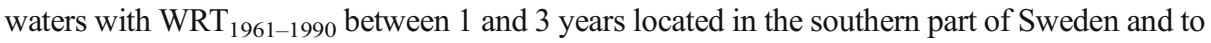
some extent at the east coast of Sweden where $\mathrm{a}_{420}$ at present is relatively high (Figs. $3 \mathrm{a}$ and 4a) and where it is going to increase by factors between 1.5 and 2.5 (Fig. 3d). In these waters preparedness for the preparation of drinking water is needed under the predicted future climate change. The Swedish Lake Mälaren with $\mathrm{WRT}_{1961-1990}$ of about 2.8 years is an example where recent trends in water color have caused problems for the preparation of drinking water (Köhler et al. 2013). Similar problems are known from other parts of the world (Roulet and Moore 2006).

Our worst case predictions considered a homogenous $10 \%$ increase in $\mathrm{a}_{420}$ in headwaters but no change in land-cover. Land-cover was indirectly included as an input variable in the $\mathrm{a}_{420}$ model when we used MAT $_{1961-1990}$ for the prediction of $\mathrm{a}_{420 \text {,headwater }}$ MAT $_{1961-1990}$ turned out to be the most important driver for $\mathrm{a}_{420 \text {,headwater }}$ spatial variation, most probably 


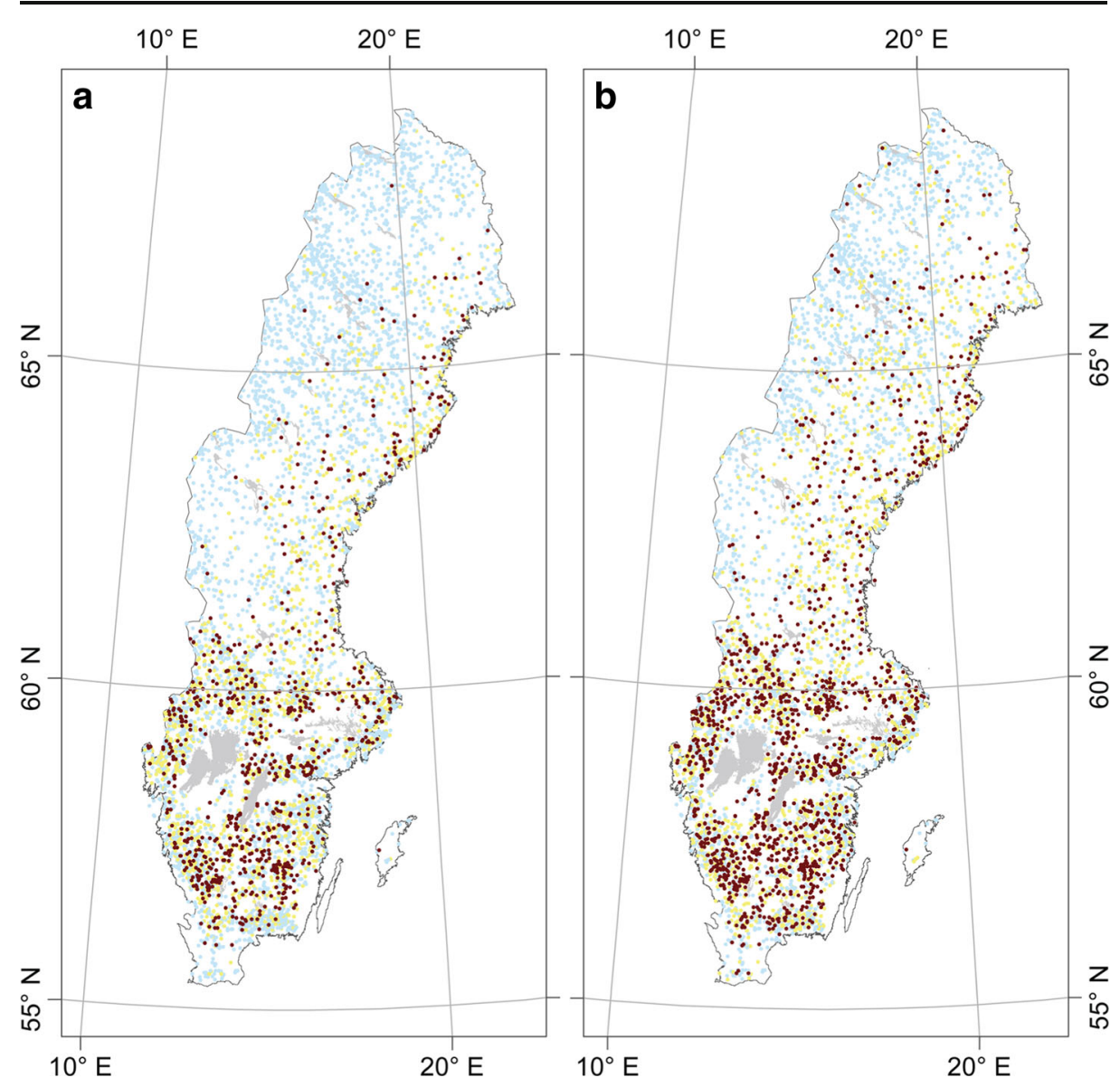

Fig 4 Map of Sweden showing the present long-term median absorbance of filtered water at $420 \mathrm{~nm}\left(\mathrm{a}_{420}\right)$ in 6347 Swedish lakes and streams (panel a) and predicted $\mathrm{a}_{420}$ in the 6347 Swedish waters under the worst case climate scenario (see text, panel b). The red color represents waters with $\mathrm{a}_{420}>20 \mathrm{~m}^{-1}$, the yellow color waters with $\mathrm{a}_{420}$ between 10 and $20 \mathrm{~m}^{-1}$ and blue waters with $\mathrm{a}_{420}<10 \mathrm{~m}^{-1}$

because MAT $_{1961-1990}$ in Sweden is a suitable proxy for land-cover variation, runoff season length and $\mathrm{RAD}_{1961-1990}$, here shown by significant relationships between $\mathrm{MAT}_{1961-1990}$ and a variety of land-cover variables, between $\mathrm{MAT}_{1961-1990}$ and $\mathrm{GDD}_{1961-1990}$, and between MAT $_{1961-1990}$ and RAD ${ }_{1961-1990 .}$ Land-cover as the main driver of colored dissolved organic matter, in this study measured as $\mathrm{a}_{420}$, is well known (Dillon and Molot 1997; Kortelainen et al. 2006). Also runoff season length and global radiation as important drivers for $\mathrm{a}_{420}$ variation are well documented (Vähätalo et al. 2000; Vodacek et al. 1997; Weyhenmeyer et al. 2014). Thus, MAT $_{1961-199)}$ in Sweden represents many catchment and climate variables which are known to drive $\mathrm{a}_{420}$ spatial variation. The relationship between $\mathrm{MAT}_{1961-1990}$ and $\mathrm{a}_{420 \text {,head- }}$ water was hump-shaped with maximum $\mathrm{a}_{420}$ at $\mathrm{MAT}_{1961-1990}$ between 4 and $6{ }^{\circ} \mathrm{C}$ (Fig. 1). A hump-shaped relationship to $\mathrm{MAT}_{1961-1990}$ has been found earlier, not for $\mathrm{a}_{420}$ but for DOC concentrations in streams (Laudon et al. 2012). To understand the underlying mechanism for such a hump-shaped relationship, i.e., to understand whether the relationship is caused by land-cover patterns, by a shift from transport to production limited systems as suggested by 
Laudon et al. (2012) or by other mechanisms, we would need far more data from various headwaters and over a longer time period which were not available to us. To model $\mathrm{a}_{420 \text {,head- }}$ water is a challenge but urgently needed to predict browning of freshwaters.

Land-cover remained similar during the past 25 years in the catchments of our 24 lakes and 24 streams. Consequently, MAT $_{1961-1990}$ was still a suitable model input variable when we predicted $\mathrm{a}_{420}$ in the headwaters of the 48 waters. Although our simple numerical $\mathrm{a}_{420}$ model was not able to capture inter-annual variations in individual waters in all details, our observations and model simulations clearly showed that precipitation was one of the most important drivers for inter-annual variations in $\mathrm{a}_{420}$. Both trend analyses and model results further demonstrated that the observed increase in $\mathrm{a}_{420}$ in the 48 waters during the past 25 years was substantially faster than the concurrent precipitation increase. One obvious explanation for accelerated $\mathrm{a}_{420}$ increases is an increased soil export of colored dissolved organic matter. Increased soil export of colored dissolved organic matter has previously been related to decreasing sulfate deposition (Ekström et al. 2011; Evans et al. 2012; Monteith et al. 2007; Tipping and Hurley 1988). On a spatial scale we found no evidence that $\mathrm{SO}_{4}-\mathrm{S}$ concentrations have an influence on $\mathrm{a}_{420}$ variation, probably because of an overriding effect of land-cover. On a temporal scale, however, $a_{420}$ could potentially have increased in headwaters as a result of decreased sulfate deposition during the past 25 years. We have no suitable data to confirm or deny this statement. Our sensitivity analyses showed however that $\mathrm{a}_{420}$ in waters with a long WRT $_{1961-1990}$ are affected more by runoff changes than by changes in headwater conditions (Fig. 3b).

If accelerated $\mathrm{a}_{420}$ increases in downstream waters might not primarily be a result of an increased soil export of colored dissolved organic matter then other explanations are needed. Accelerated $\mathrm{a}_{420}$ increases in downstream waters can, for example, occur if runoff patterns through the landscape change. Runoff patterns are complex, and to model these in detail on large scales where also groundwater flows as well as precipitation intensity, duration and timing need to be considered goes beyond this study. However, we have indications that colored dissolved organic matter from soils is not equally diluted on the way downstream when precipitation increases. When we modeled $\mathrm{a}_{420}$ inter-annual variation over the past 25 years we needed to recalibrate our $\mathrm{a}_{420}$ model where the parameter Lakedepth $\mathrm{mean}_{\text {was }}$ reduced from 4 to $3 \mathrm{~m}$. Thus, it seems that not the entire lake volumes are flushed when precipitation increases, resulting in a rapid $\mathrm{a}_{420}$ increase in surface waters of downstream waters. Also the fact that the increase in $\mathrm{a}_{420}$ was significantly faster in lakes than in streams might give further evidence that an increase in precipitation focuses the flushing through lakes into a smaller fraction of the lake volume. In our worst case scenario we assumed that only the upper $1 \mathrm{~m}$ of the water bodies is flushed by the predicted strong precipitation increase. Although this might be unrealistic over a longer time period it might occur over a short time period under extreme precipitation events. These short pulse events are important to capture as they have far-reaching implications for the preparation of drinking water and other ecosystem services.

An accelerated $\mathrm{a}_{420}$ increase in waters with long $\mathrm{WRT}_{1961-1990}$ can also result from a decrease in the decay coefficient $\lambda$, corresponding to longer $\mathrm{a}_{420}$ half-lives. The $\mathrm{a}_{420}$ half-life which we calibrated in this study was shorter than previously found on a large scale (Algesten et al. 2004; Weyhenmeyer et al. 2012) and within a large lake basin (Köhler et al. 2013) but longer than on a small catchment scale (Moody et al. 2013). According to laboratory studies, $\lambda$ is not constant but decreases the longer colored dissolved organic matter has been subjected to transformation processes (Koehler et al. 2012). Thus, it is possible that $\lambda$ decreases but only if 
landscape WRT increases. Since we propose that landscape WRT has decreased over the past decades, it is highly unlikely that $\lambda$ has decreased.

The numerical $\mathrm{a}_{420}$ model was kept very simple and required only very few input variables and parameters so that $\mathrm{a}_{420}$ in thousands of waters could be predicted. The weakest part of the

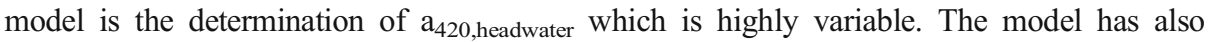
limitations when it comes to capture short-term $\mathrm{a}_{420}$ variations as a response to extreme runoff events, and a basic assumption of the model is that $\mathrm{a}_{420}$ transformations during transport from land to sea are mainly driven by hydrological processes. Despite these limitations the model is powerful in demonstrating differences in $\mathrm{a}_{420}$ responses to runoff changes depending on WRT $_{1961-1990}$ of the waters. And although the model was calibrated for Swedish conditions,

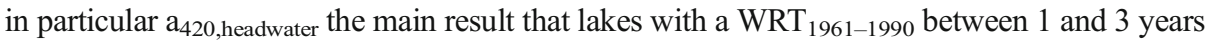
are particularly vulnerable to precipitation driven browning is valid for all waters that are hydrologically connected in the landscape.

\section{Conclusions}

Our study clearly demonstrates that both headwater conditions and $\mathrm{a}_{420}$ transformation during transport through the landscape need to be understood in order to predict future browning of freshwaters. Headwater conditions are highly variable. On the spatial scale headwater conditions are strongly driven by land-cover. We suggest that small changes in land-cover will most probably result in $\mathrm{a}_{420}$ changes that are substantially faster than the direct climate change induced $\mathrm{a}_{420}$ changes. Thus, priority in managing $\mathrm{a}_{420}$ should be put on managing land-cover. Direct climate change induced $\mathrm{a}_{420}$ changes become particularly apparent in downstream waters which we conclude from the observation that a homogenous precipitation increase caused an increasing $\mathrm{a}_{420}$ response along a landscape WRT $_{1961-1990}$ gradient. Such large differences in $\mathrm{a}_{420}$ responses to the same climate change should be taken into account when water color risk assessments are done.

Acknowledgments Financial support was received from the Swedish Research Council (VR) and the Swedish Research Council for Environment, Agricultural Sciences and Spatial Planning (FORMAS). This work is part of and profited from the networks financed by NordForsk (CRAICC and DOMQUA) and the Norwegian Research Council (Norklima ECCO). Many thanks go to the Swedish Environmental Protection Agency and the staff of the laboratory of the Dept. of Aquatic Sciences and Assessment for financing, sampling and analyzing thousands of water samples, and to the Swedish Meteorological and Hydrological Institute for making meteorological data freely available. GIS data were kindly received from Jakob Nisell. Finally, we thank Nigel Roulet and two unknown reviewers for excellent reviews.

Open Access This article is distributed under the terms of the Creative Commons Attribution 4.0 International License (http://creativecommons.org/licenses/by/4.0/), which permits unrestricted use, distribution, and reproduction in any medium, provided you give appropriate credit to the original author(s) and the source, provide a link to the Creative Commons license, and indicate if changes were made.

\section{References}

Algesten G, Sobek S, Bergström AK, Ågren A, Tranvik LJ, Jansson M (2004) Role of lakes for organic carbon cycling in the boreal zone. Glob Chang Biol 10:141-147

Canham CD, Pace ML, Papaik MJ, Primack AGB, Roy KM, Maranger RJ, Curran RP, Spada DM (2004) A spatially explicit watershed-scale analysis of dissolved organic carbon in Adirondack lakes. Ecol Appl 14:839-854 
Dillon PJ, Molot LA (1997) Effect of landscape form on export of dissolved organic carbon, iron, and phosphorus from forested stream catchments. Water Resour Res 33:2591-2600

Eikebrokk B, Vogt RD, Liltved H (2004) NOM increase in Northern European source waters: discussion of possible causes and impacts on coagulation/contact filtration processes. In: Newcombe G, Ho L (eds) Natural Organic Material Research: Innovations and Applications for Drinking Water. Water Science and Technology: Water Supply, vol 4. IWA Publishing, London, p 47-54

Ekström SM, Kritzberg ES, Kleja DB, Larsson N, Nilsson PA, Graneli W, Bergkvist B (2011) Effect of acid deposition on quantity and quality of dissolved organic matter in soil-water. Environ Sci Technol 45:4733-4739

Erlandsson M, Buffam I, Folster J, Laudon H, Temnerud J, Weyhenmeyer GA, Bishop K (2008) Thirty-five years of synchrony in the organic matter concentrations of Swedish rivers explained by variation in flow and sulphate. Glob Chang Biol 14:1191-1198

Evans CD, Chapman PJ, Clark JM, Monteith DT, Cresser MS (2006) Alternative explanations for rising dissolved organic carbon export from organic soils. Glob Chang Biol 12:2044-2053

Evans CD, Jones TG, Burden A, Ostle N, Zielinski P, Cooper MDA, Peacock M, Clark JM, Oulehle F, Cooper D, Freeman C (2012) Acidity controls on dissolved organic carbon mobility in organic soils. Glob Chang Biol 18:3317-3331

Hu CM, Muller-Karger FE, Zepp RG (2002) Absorbance, absorption coefficient, and apparent quantum yield: a comment on common ambiguity in the use of these optical concepts. Limnol Oceanogr 47:1261-1267

Kirk JTO (2003) Light and photosynthesis in aquatic ecosystems. Cambridge University Press, Cambridge

Koehler B, von Wachenfeldt E, Kothawala D, Tranvik LJ (2012) Reactivity continuum of dissolved organic carbon decomposition in lake water. J Geophys Res Biogeosci 117. doi:10.1029/2011jg001793

Köhler SJ, Kothawala D, Futter MN, Liungman O, Tranvik L (2013) In-lake processes offset increased terrestrial inputs of dissolved organic carbon and color to lakes. Plos One 8. doi:10.1371/journal.pone.0070598

Kortelainen P (1993) Content of total organic-carbon in Finnish lakes and its relationship to catchment characteristics. Can J Fish Aquat Sci 50:1477-1483

Kortelainen P, Mattsson T, Finer L, Ahtiainen M, Saukkonen S, Sallantaus T (2006) Controls on the export of C, N, P and Fe from undisturbed boreal catchments, Finland. Aquat Sci 68:453-468

Kritzberg ES, Ekström SM (2012) Increasing iron concentrations in surface waters - a factor behind brownification? Biogeosciences 9:1465-1478

Larsen S, Andersen T, Hessen DO (2011) Predicting organic carbon in lakes from climate drivers and catchment properties. Glob Biogeochem Cycles 25. doi:10.1029/2010gb003908

Laudon H, Buttle J, Carey SK, McDonnell J, McGuire K, Seibert J, Shanley J, Soulsby C, Tetzlaff D (2012) Cross-regional prediction of long-term trajectory of stream water DOC response to climate change. Geophys Res Lett 39. doi:10.1029/2012g1053033

Livingstone DM, Lotter AF, Walker IR (1999) The decrease in summer surface water temperature with altitude in swiss alpine lakes: a comparison with air temperature lapse rates. Arct Antarct Alp Res 31:341-352

Molot LA, Dillon PJ (1997) Colour - mass balances and colour - dissolved organic carbon relationships in lakes and streams in central Ontario. Can J Fish Aquat Sci 54:2789-2795

Monteith DT, Stoddard JL, Evans CD, de Wit HA, Forsius M, Hogasen T, Wilander A, Skjelkvale BL, Jeffries DS, Vuorenmaa J, Keller B, Kopacek J, Vesely J (2007) Dissolved organic carbon trends resulting from changes in atmospheric deposition chemistry. Nature 450:537-540

Moody CS, Worrall F, Evans CD, Jones TG (2013) The rate of loss of dissolved organic carbon (DOC) through a catchment. J Hydrol 492:139-150

Müller RA, Futter MN, Sobek S, Nisell J, Bishop K, Weyhenmeyer GA (2013) Water renewal along the aquatic continuum offsets cumulative retention by lakes: implications for the character of organic carbon in boreal lakes. Aquat Sci 75:535-545

Pace ML, Cole JJ (2002) Synchronous variation of dissolved organic carbon and color in lakes. Limnol Oceanogr 47:333-342

Richardson SD (2007) Water analysis: emerging contaminants and current issues. Anal Chem 79:4295-4323

Roulet N, Moore TR (2006) Environmental chemistry - browning the waters. Nature 444:283-284

Sobek S, Tranvik LJ, Prairie YT, Kortelainen P, Cole JJ (2007) Patterns and regulation of dissolved organic carbon: an analysis of 7500 widely distributed lakes. Limnol Oceanogr 52:1208-1219

Thurman EM (1985) Organic geochemistry of natural waters. Nijhoff/Junk, Boston

Tipping E, Hurley MA (1988) A model of solid-solution interactions in acid organic soils, based on the complexation properties of humic substances. J Soil Sci 39:505-519

Vähätalo AV, Salkinoja-Salonen M, Taalas P, Salonen K (2000) Spectrum of the quantum yield for photochemical mineralization of dissolved organic carbon in a humic lake. Limnol Oceanogr 45:664-676

Vodacek A, Blough NV, DeGrandpre MD, Peltzer ET, Nelson RK (1997) Seasonal variation of CDOM and DOC in the Middle Atlantic Bight: terrestrial inputs and photooxidation. Limnol Oceanogr 42:674-686 
Volk C, Wood L, Johnson B, Robinson J, Zhu HW, Kaplan L (2002) Monitoring dissolved organic carbon in surface and drinking waters. J Environ Monit 4:43-47

Weyhenmeyer GA (2008) Water chemical changes along a latitudinal gradient in relation to climate and atmospheric deposition. Clim Change 88:199-208

Weyhenmeyer GA, Fröberg M, Karltun E, Khalili M, Kothawala D, Temnerud J, Tranvik LJ (2012) Selective decay of terrestrial organic carbon during transport from land to sea. Glob Chang Biol 18:349-355

Weyhenmeyer GA, Prairie YT, Tranvik LJ (2014) Browning of boreal freshwaters coupled to carbon-iron interactions along the aquatic continuum. Plos One 9. doi:10.1371/journal.pone.0088104

Winterdahl M, Erlandsson M, Futter MN, Weyhenmeyer GA, Bishop K (2014) Intra-annual variability of organic carbon concentrations in running waters: drivers along a climatic gradient. Global Biogeochem Cycles 28: 451-464

Xenopoulos MA, Lodge DM, Frentress J, Kreps TA, Bridgham SD, Grossman E, Jackson CJ (2003) Regional comparisons of watershed determinants of dissolved organic carbon in temperate lakes from the Upper Great Lakes region and selected regions globally. Limnol Oceanogr 48:2321-2334 